\title{
Planned Number of Male Subjects
}

National Cancer Institute

\section{Source}

National Cancer Institute. Planned Number of Male Subjects. NCI Thesaurus. Code C90438.

The intended quantity of male participants. 